(C) 1981. The Genetical Society of Great Britain

\title{
COLOUR OF FLORAL PARTS IN NICOTIANA RUSTICA
}

\author{
H. S. POONI and J. L. JINKS \\ Department of Genetics, University of Birmingham, Birmingham B15 2TT
}

Received 13.xi.80

\section{INTRODUCTION}

THIs note records the cumulative information on the genetical control of the colour of floral parts in Nicotiana rustica and the genotypes of the more widely grown varieties in respect of the controlling loci.

Nicotiana rustica is an allopolyploid with $2 n=4 x=48$ chromosomes which has originated from intercrossing of two diploid species Nicotiana paniculata $(2 n=2 x=24)$ and Nicotiana undulata $(2 n=2 x=24)$. The chromosome complements from both of these species are represented in full in the new species and there is little evidence of any significant genetic loss during speciation (Goodspeed, 1954). We would expect therefore that the genes controlling floral and ovary colour for either of these diploids should also be duplicated in the allotetraploid.

Previous evidence shows that the presence (black) and absence of anthocyanin in the floral parts is under the control of two alleles $(A, a)$ at a single locus with presence dominant to absence (Mather and Vines, 1952). Yellow vs. non-yellow (black or green) floral parts, however, segregate with the frequencies expected if controlled by two unlinked loci with non-yellow displaying dominant epistasis to yellow which is the multiple recessive phenotype (Jinks, 1954). At one or both loci we could, therefore, have three alleles $A, a$ and $y$. On the assumption that all three alleles can occur at each of the two loci, nine possible homozygous genotypes can be expected among the three phenotypes, black, green and yellow which are most clearly expressed in the immature ovary.

\begin{tabular}{|c|c|c|}
\hline Number & Genotype & Ovary colour \\
\hline $\begin{array}{l}1 \\
2 \\
3 \\
4 \\
5\end{array}$ & $\begin{array}{c}A_{1} A_{1} A_{2} A_{2} \\
A_{1} A_{1} a_{2} a_{2} \\
a_{1} a_{1} A_{2} A_{2} \\
A_{1} A_{1} y_{2} y_{2} \\
y_{1} y_{1} A_{2} A_{2}\end{array}$ & Black \\
\hline $\begin{array}{l}6 \\
7 \\
8\end{array}$ & $\begin{array}{l}a_{1} a_{1} a_{2} a_{2} \\
a_{1} a_{1} y_{2} y_{2} \\
y_{1} y_{1} a_{2} a_{2}\end{array}$ & Green \\
\hline 9 & $y_{1} y_{1} y_{2} y_{2}$ & Yellow \\
\hline
\end{tabular}

On the basis of the parental and $F_{1}$ phenotypes and the segregations in the $\mathrm{F}_{2}, \mathrm{BC}_{1}$ and $\mathrm{BC}_{2}$ famili_s of all possible pairwise crosses among these nine homozygotes we can generate expectations which will allow us to test this explanation of the genetical control of floral phenotype and classify the most widely used varieties of Nicotiana rustica in respect of these loci. The expected segregation ratios are tabulated in table 1. 
TABLE 1

Expected segregation ratios in the $F_{1}, F_{2}$ and first backcross generations $\left(B C_{1}\right.$ and $\left.B C_{2}\right)$ of the pairwise crosses between all nine possible homozygotes in respect of two loci with three alleles per locus

\begin{tabular}{|c|c|c|c|c|c|}
\hline & & & Gen & ions & \\
\hline lassification & Cross & $\begin{array}{c}\mathrm{F}_{1} \\
\mathrm{~B}: \mathrm{G}: \mathrm{Y}^{*}\end{array}$ & $\begin{array}{c}F_{2} \\
B: G: Y\end{array}$ & $\begin{array}{c}\mathrm{BC}_{1} \\
\mathrm{~B}: \mathrm{G}: \mathrm{Y}\end{array}$ & $\begin{array}{c}\mathrm{BC}_{2} \\
\mathrm{~B}: \mathrm{G}: \mathrm{Y}\end{array}$ \\
\hline
\end{tabular}

(a) Black $\times$ Black crosses

$\begin{array}{cccccc}1 \times 1,1 \times 2,1 \times 3, & \text { All black } & \text { All black } & \text { All black } & \text { All black } \\ & \begin{array}{c}1 \times 4,1 \times 5,2 \times 2, \\ 2 \times 4,3 \times 3,3 \times 5, \\ 4 \times 4,5 \times 5\end{array} & & & \\ & 2 \times 3,3 \times 4 & \text { All black } & 15: 1: 0 & \text { All black } & 3: 1: 0 \\ 2 & 2 \times 5 & \text { All black } & 15: 1: 0 & \text { All black } & \text { All black } \\ 3 & 4 \times 5 & \text { All black } & 15: 0: 1 & \text { All black } & \text { All black }\end{array}$

(b) Black $\times$ Green crosses

\begin{tabular}{|c|c|c|c|c|c|}
\hline 1 & $1 \times 6,1 \times 7,1 \times 8$ & All black & $15: 1: 0$ & All black & $3: 1: 0$ \\
\hline 2 & $\begin{array}{c}2 \times 6,2 \times 7,2 \times 8, \\
3 \times 6,3 \times 7,3 \times 8, \\
4 \times 6,4 \times 7,5 \times 6, \\
5 \times 8\end{array}$ & All black & $3: 1: 0$ & All black & $1: 1: 0$ \\
\hline 3 & $4 \times 8,5 \times 7$ & All black & $12: 3: 1$ & All black & $1: 1: 0$ \\
\hline \multicolumn{6}{|c|}{ (c) Black $\times$ Yellow crosses } \\
\hline 1 & $1 \times 9$ & All black & $15: 0: 1$ & All black & $3: 0: 1$ \\
\hline 2 & $2 \times 9,3 \times 9$ & All black & $12: 3: 1$ & All black & $2: 1: 1$ \\
\hline 3 & $4 \times 9,5 \times 9$ & All black & $3: 0: 1$ & All black & $1: 0: 1$ \\
\hline \multicolumn{6}{|c|}{ (d) Green $\times$ Green crosses } \\
\hline 1 & $\begin{array}{c}6 \times 6,6 \times 7,6 \times 8 \\
7 \times 7,8 \times 8\end{array}$ & All Green & All Green & All Green & All Green \\
\hline 2 & $7 \times 8$ & All Green & $0: 15: 1$ & All Green & All Green \\
\hline \multicolumn{6}{|c|}{ (e) Green $\times$ Yellow crosses } \\
\hline 1 & $6 \times 9$ & All Green & $0: 15: 1$ & All Green & $0: 3: 1$ \\
\hline 2 & $7 \times 9,8 \times 9$ & All Green & $0: 3: 1$ & All Green & $0: 1: 1$ \\
\hline \multicolumn{6}{|c|}{ (f) Yellow $\times$ Yellow crosses } \\
\hline 1 & $9 \times 9$ & All Yellow & All Yellow & All Yellow & All Yellow \\
\hline
\end{tabular}

\section{Results}

Unpublished data from many sources, for example, the breeding programmes of Jinks (1954) and Virk (1976) and others are summarised in table 2 . Where data from independent crosses are homogeneous they have been pooled, which reduces them to seven sets. Each set fits only one of the expectations given in table 1 . The two locus, triallelic model, therefore, accounts for the observed data and the genotypes of the varieties on this model are given in table 3. Among these only four of the nine possible homozygotes are represented and they require that the $a$ and $y$ alleles occur at both loci and the $A$ allele at one of them. 
TABLE 2

Proportions of Black: Green: Yellow ovaried plants in the basic generations of various crosses

\begin{tabular}{|c|c|c|c|c|c|c|}
\hline \multicolumn{3}{|c|}{ Crosses } & \multicolumn{4}{|c|}{ Generations } \\
\hline $\begin{array}{c}\text { Parental } \\
\text { phenotypes }\end{array}$ & & $\begin{array}{l}\text { Parental } \\
\text { varieties }\end{array}$ & $\mathrm{F}_{1}$ & $\mathrm{~F}_{2}$ & $\mathrm{BC}_{1}$ & $\mathrm{BC}_{2}$ \\
\hline ack $\times$ Black & (a) $1^{*}$ & $V_{1} \times V_{12}$ & $8: 0: 0$ & $80: 0: 0$ & $80: 0: 0$ & $79: 0: 0$ \\
\hline ack $\times$ Green & (b) 2 & $\begin{array}{l}V_{12} \times\left(V_{2}, V_{5}\right. \\
\left.V_{7}, V_{29} \text { and } V_{38}\right)\end{array}$ & $297: 0: 0$ & $302: 93: 0$ & $198: 0: 0$ & $72: 87: 0$ \\
\hline ack $\times$ Yellow & (c) 2 & $\begin{array}{l}V_{12} \times\left(V_{14} \text { and }\right. \\
\left.V_{41}\right)\end{array}$ & $118: 0: 0$ & $102: 43: 5$ & $80: 0: 0$ & $21: 37: 8$ \\
\hline een $\times$ Green & (d) 1 & $\begin{array}{l}\text { Pairwise crosses } \\
\text { between } V_{2}, V_{5} \text {, } \\
V_{7}, V_{29} \text { and } V_{38}\end{array}$ & $0: 596: 0$ & $0: 749: 0$ & $0: 396: 0$ & $0: 396: 0$ \\
\hline reen $\times$ Yellow & (e) 1 & $\begin{array}{l}\left(V_{2}, V_{5}, V_{29} \text { and }\right. \\
\left.V_{38}\right) \times\left(V_{14} \text { and }\right. \\
\left.V_{41}\right) \text { and } V_{22} \times \\
\left(V_{14}, V_{27}, \quad V_{34},\right. \\
V_{72}, \quad V_{73} \text { and } \\
\left.V_{80}\right)\end{array}$ & $0: 788: 0$ & $0: 1466: 91$ & $0: 1019: 0$ & $0: 757: 272$ \\
\hline een $\times$ Yellow & (e) 2 & $\begin{array}{l}V_{7} \times\left(V_{14} \text { and }\right. \\
\left.V_{41}\right)\end{array}$ & $0: 118: 0$ & $0: 116: 44$ & $0: 80: 0$ & $0: 35: 35$ \\
\hline llow $\times$ Yellow & (f) 1 & $V_{14} \times V_{41}$ & $0: 0: 60$ & $0: 0: 78$ & $0: 0: 40$ & $0: 0: 40$ \\
\hline
\end{tabular}

* See table 1.

TABLE 3

Genotypes of varieties of Nicotiana rustica in respect of the two loci controlling ovary colur

\begin{tabular}{ccl} 
Variety & Ovary Phenotype & \multicolumn{1}{c}{ Genotype } \\
$V_{1}$ & Black & $A_{1} A_{1} a_{2} a_{2}$ (or $\left.a_{1} a_{1} A_{2} A_{2}\right)^{*}$ \\
$V_{2}$ & Green & $a_{1} a_{1} a_{2} a_{2}$ \\
$V_{5}$ & Green & $a_{1} a_{1} a_{2} a_{2}$ \\
$V_{7}$ & Green & $a_{1} a_{1} y_{2} y_{2}$ (or $y_{1} y_{1} a_{2} a_{2}$ ) \\
$V_{12}$ & Black & $A_{1} A_{1} a_{2} a_{2}$ (or $\left.a_{1} a_{1} A_{2} A_{2}\right)^{*}$ \\
$V_{14}$ & Yellow & $y_{1} y_{1} y_{2} y_{2}$ \\
$V_{22}$ & Green & $a_{1} a_{1} a_{2} a_{2}$ \\
$V_{27}$ & Yellow & $y_{1} y_{1} y_{2} y_{2}$ \\
$V_{29}$ & Green & $a_{1} a_{1} a_{2} a_{2}$ \\
$V_{34}$ & Yellow & $y_{1} y_{1} y_{2} y_{2}$ \\
$V_{38}$ & Green & $a_{1} a_{1} a_{2} a_{2}$ \\
$V_{41}$ & Yellow & $y_{1} y_{1} y_{2} y_{2}$ \\
$V_{72}$ & Yellow & $y_{1} y_{1} y_{2} y_{2}$ \\
$V_{73}$ & Yellow & $y_{1} y_{1} y_{2} y_{2}$ \\
$V_{80}$ & Yellow & $y_{1} y_{1} y_{2} y_{2}$
\end{tabular}

Varieties $V_{1}$ and $V_{12}$ are identical genotypes. So either they are both $A_{1} A_{1} a_{2} a_{2}$ or $a_{1} a_{1} A_{2} A_{2}$.

\section{REFERENCES}

GoOdspeed, T. H. 1954. The Genus Nicotiana. Chronica Botanica, 16, Waltham, Mass. JINKS, J. L. 1954. The analysis of continuous variation in a diallel cross of Nicotiana rustica varieties. Genetics, 39, 767-788.

MATHER, K., AND VINES, A. 1952. The inheritance of height and flowering time in a cross of Nicotiana rustica. In Quantitative Inheritance, (ed. E. C. R. Reeve and C. N. Waddington, pp. 49-80. H.M.S.O., London.

VIRK, D. S. 1976. Application of biometrical genetics and matromorphy to plant breeding. Ph.D thesis, University of Birmingham. 